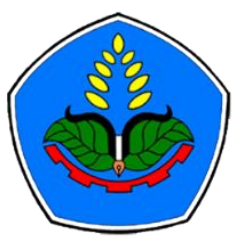

AGROPROSS

National Conference

Proceedings of Agriculture

\section{Proceedings: \\ Peran Teaching Factory Di Perguruan Tinggi Vokasi Dalam \\ Mendukung Ketahanan Pangan Pada Era New Normal}

Tempat : Politeknik Negeri Jember

Tanggal : 8-9 Juli 2020

\section{Publisher:}

Agropross, National Conference Proceedings of Agriculture

ISBN : 978-623-94036-6-9

DOI : 10.25047/agropross.2020.39

\title{
Sistem Polder Untuk Pengendali Tinggi Muka Air Lahan Sawah Rawa Lebak
}

\author{
Author(s): Edward Saleh ${ }^{(1)^{*}}$ \\ (1) Prodi Teknik Pertanian, Universitas Sriwijaya \\ * Corresponding author: edward.saleh@fp.unsri.ac.id
}

\begin{abstract}
Rawa Lebak is an ecology that is submerged in water during the period of the rainy season and drought in the dry season period. When submerged in water, the water level cannot be controlled by gravity, so that the water level in the Rawa Lebak fields cannot meet the needs of the plants. Conversely, during the dry season paddy fields will dry up, plants will experience water shortages. One of the technologies developed by the community to control water in swampy swamps is with a mini polder of 250-1000 ha. The design of this polder system control is carried out by constructing a water reservoir, drainage pump and irrigation water. The results showed that the polder system was able to increase cropping intensity from one time per year (IP 100) to three times per year (IP300), with a rice-paddy-cropping pattern.
\end{abstract}

Keyword:

Rawa Lebak;

Polder System;

Ricefield;

\section{Kata Kunci: $\quad$ ABSTRAK \\ Rawa lebak merupakan ekologi yang terendam air pada periode waktu musim hujan dan kekeringan \\ Rawa Lebak; $\quad$ pada periode musim kemarau. Pada saat terendam air, tinggi muka air tidak dapat dikendalikan \\ Sistem Polder; $\quad$ secara gravitasi, sehingga tinggi muka air dilahan sawah rawa lebak tidak dapat memenuhi sesuai \\ kebutuhan tanaman. Sebaliknya pada waktu musim kemarau lahan sawah akan kering, tanaman \\ Sawah; akan mengalami kekurangan air. Salah satu teknologi yang dikembangkan masyarakat untuk mengendalikan air dilahan rawa lebak dengan polder mini yang luasnya 250 - 1000 ha. Rancangan pengendalian sistem polder ini dilaku dengan membangun saluran penampung air, pompa pembuang (drainase) dan pemasuk (irigasi) air. Hasil penelitian menunjukkan dengan sistem polder telah mampu meningkatkan intensitas tanam dari satu kali pertahun (IP 100) menjadi tiga kali tanam pertahun (IP300), dengan pola tanam padi-padi-palawija.}




\section{PENDAHULUAN}

Tahun 1985 Indonesia mengklaim mencapai swasembada beras, namun setelah itu kembali menjadi pengimpor beras. Gagalnya mempertahankan swasembada beras disebabkan berkurangnya luas lahan akibat konversi lahan sawah disekitar perkotaan, dan melandainya produktifitas lahan. Berbagai upaya telah dilakukan untuk mencapai swasembada beras kembali, diantaranya melalui intensifikasi dan ekstensifikasi. Intensifikasi dengan meningkatkan masukan teknologi untuk memproduksi beras. Ekstensifikasi dilakukan dengan membuka lahan baru potensial, seperti lahan rawa lebak dan rawa pasang surut.

Usaha intensifikasi besar-besaran untuk mengenjot produksi lahan dengan meningkatkan input teknologi dilaksanakan sejak tahun 2015 sampai dengan tahun 2019. Kementerian Pertanian pada periode tersebut gencar melakukan perbaikan infrastruktur pertanian, penyediaan bantuan alat dan mesin pertanian panen dan pascapanen, yang diharapkan dapat meningkatkan Intensitas pertanaman (IP). Sedangkan usaha ekstensifikasi dilakukan dengan membuka lahan sawah baru, dan akhir-akhir ini menyasar ke lahan rawa.

Menurut Noor dan Mukhlis (2019) usaha menjadikan lahan rawa sebagai lumbung pangan merupakan tuntutan, karena adanya tuntutan dari pertambahan penduduk 3 juta orang per tahun dan berkurangnya luas lahan sawa produktif 100.000 ha per tahun. Data BBSDLP tahun 2016 menunjukkan luas lahan rawa yang potensial untuk tanaman padi sawah mencapai 14,18 juta hektar. Dari luasan tersebut, diperkirakan

6,0-6,5 juta hektar yang telah dimanfaatkan dan hanya 3,0-3,5 juta hektar yang menjadi sawah (BBSDLP, 2016)

Lahan rawa yang dikenal dengan lahan sub-optimal mempunyai karakter atau watak tersendiri yang berbeda dengan agroekosistem lahan kering, tadah hujan atau lahan irigasi (Noor, Khairullah dan Sosiawan, 2019). Rawa lebak merupakan ekologi yang terendam air pada periode waktu musim hujan dan kekeringan pada periode musim kemarau. Pada saat terendam air, tinggi muka air tidak dapat dikendalikan secara gravitasi, sehingga tinggi muka air dilahan sawah rawa lebak tidak dapat memenuhi sesuai kebutuhan tanaman. Sebaliknya pada waktu musim kemarau lahanakan kering, tanaman akan mengalami kekurangan air dan air tidak dapat dimasukkan secara gravitasi. Karena itu untuk optimalisasi lahan rawa lebak yang tergolong lahan suboptimal, diperlukan pengendalian tinggi muka air di lahan.

Tulisan ini bertujuan untuk memberikan pemikiran pengendalian tinggi muka air dilahan sawah rawa lebak agar dapat meningkatkan Intensitas Pertanaman (IP) dalam satu tahun dan meningkatkan produktivitas lahan.

\section{METODOLOGI}

Penelitian telah dilakukan di daerah rawa lebah Ogan Keramasan, Kabupaten Ogan Ilir, Provinsi Sumatera Selatan pada tahun 2018-2019. Metode penelitian dilakukan dengan studi pustaka dan pengamatan lapangan. Studi pustaka dilakukan dengan menelusuri hasil-hasil penelitian berkaitan dengan pengelolaan air lahan rawa lebak, dan catatan data curah hujan sebagai data sekunder. Data primer diperoleh melalui pengamatan lapangan. Kegiatan pengamatan lapangan dilakukan dengan observasi tinggi muka air dilahan, waktu tanam, Intensitas Pertanaman (IP), operasional pengendalian tinggi mukair dilahan sawah, operasional pompa air, operasional di lahan sistem polder.

\section{HASIL DAN PEMBAHASAN}

Lahan rawa lebak Ogan Keramasan merupakan lahan rawa yang diapit oleh dua sungai, yaitu sungai Ogan dan sungai Keramasan. Air rawa berasal dari limpahan 
sungai Ogan yang luas DAS nya lebih luas dari sungai Keramasan, dan karena lahannya relatif datar maka akan terjadi genangan yang sangat luas, mencapai 20.000 ha.

Hasil penelitian sebelumnya oleh Saleh, Irsan dan Harun (2013) menunjukkan tinggi genangan pada lebak pematang dapat mencapai $50 \mathrm{~cm}$ dengan periode tergenang terus menerus dalam satu tahun sekitar 5 bulan, tergenang terputus sekitar 4 bulan dan periode kering selama 2 bulan. Pada kondisi normal kejadian periode tergenang terus menerus pada bulan November, Desember, Januari, Februari dan Maret, tergenang terputus terjadi pada bulan April, Mei, Juni, September dan Oktober, dan periode kering terjadi pada bulan Juli dan Agustus. Dengan kondisi air genangan sebagai kendala, petani hanya mampu menanam padi secara periodik satu kali per tahun, dengan masa tanam bulan April - Mei dan panen pada bulan Agustus - Sepetember, dan setelah itu diberakan. Produktivitas lahan sawah 3 ton per ha.

Sumber air lainnya untuk tanaman pada lahan rawa lebak adalah curah hujan. Pola hujan dilokasi penelitian berdasarkan data dari stasiun Klimatologi Kenten, selama 10 tahun, sejalan dengan pola genangan. Grafik pola hujan disajikan pada Gambar 1, menunjukkan dengan kemiripan dengan pola genangan, yaitu pada bulan Mei sampai September curah hujannya rendah. Hal ini karena ada hubungan tinggi muka air di sungai dengan pola hujan didaerah hulu dan in situ.

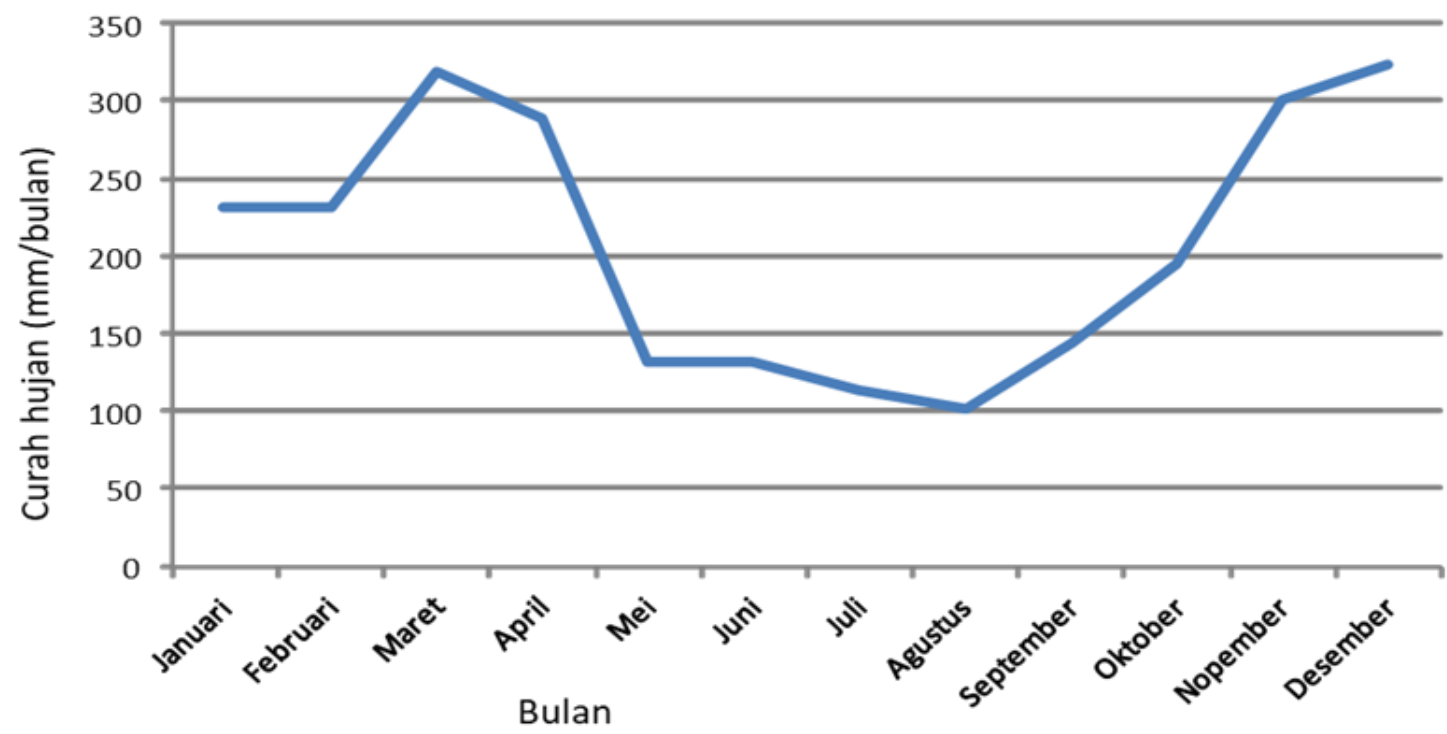

Gambar 1. Grafik pola hujan di Rawa Lebak Ogan Keramasan, berdasarkan data curah hujan stasiun klimatologi Kenten 10 tahun

Pada tahun 2015 mulai dibangun dua buah sistem polder di lahan rawa lebak Ogan Keramasan dengan luasan total mencapai 250 ha seperti ditunjukkan pada Gambar 2 oleh swasta. Lahan ini sebelumnya merupakan sawah yang diusahakan satu kali per tahun (IP 100), dengan kendala utama air, berlebihan (tinggi genangan $20-100 \mathrm{~cm}$ pada bulan-bulan
Oktober - April dan kekeringan $(-100 \mathrm{~cm})$ pada bulan Juli - September. Dengan pola genangan air seperti itu hanya memungkinkan untuk tanam padi satu kali pada bulan April sampai Agustus. Namun tidak memungkinkan menanam palawija setelah panen padi, karena tanahnya kering sampai pecah, seperti Gambar 3, dan pada bulan Oktober lahan sudah mulai tergenang air. 
Akibatnya lahan lebih banyak diberakan saja. Setelah dikonversi menjadi sistem polder, lahan tersebut dapat diusahakan IP 300 pada kondisi iklim normal, namun karena pada beberapa tahun terakhir kondisi iklim tidak normal menyebabkan polder hanya dapat diusahakan IP 200. Lahan sawah dalam sistem polder dapat tanam lebih awal (bulan Februari - Mei) sehingga dapat tanam kedua (Juni September).

Sistem polder yang telah diterapkan oleh swasta (PT. Buyung Putra Pangan) tergolong polder mini jika dibandingkan dengan polder untuk pertanian yang dikenal selama ini, yang luasnya mencapai ribuan hektar. Dan dinilai sebagai inovasi baru dalam pengelolaan air dilahan rawa lebak, dengan hasil dapat meningkat intensitas pertanaman.

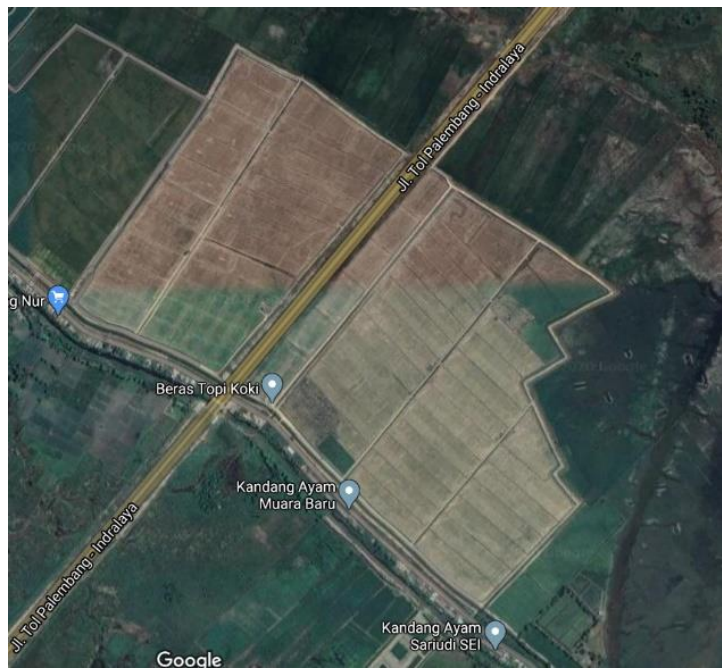

Gambar 2. Dua buah Polder di Desa Simpang Pelabuhan Dalam pada lahan rawa lebak Ogan Keramasan (sumber : google map yang diakses pada tanggal 18 Juli 2020)

Keberhasilan Sistem polder mini pertama di Simpang Pelabuhan Dalam, telah diikuti dengan pembuatan polderpolder berikutnya, diantaranya : di Desa Pemulutan (250 ha), Desa Seri Banding (177 ha), Desa Talang Pangeran (213 ha),
Olak Kembang Satu (66 ha), dan Arisan Jaya (85 ha).

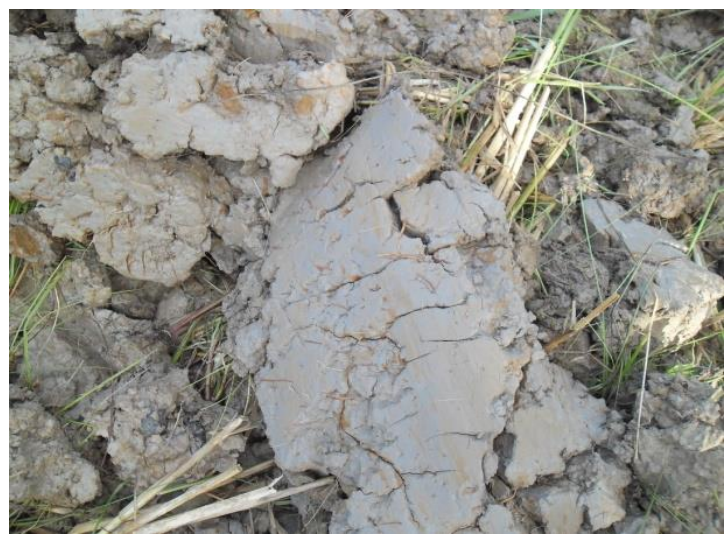

Gambar 3. Kondisi tanah yang pecah karena kekeringan.

Sistem polder mini yang diterapkan merupakan sistem tertutup, artinya lahan sawah dikurung dengan tanggul kelilig. Untuk sirkulasi, menambah atau mengeluarkan air menggunakan pompa axial. Dengan sistem air terkendali, produktivitas lahan mencapai 6 ton per ha dan tanam 2 kali per tahun. Pengelolaan sistem polder oleh swasta ini membutuhkan biaya operasi pompa dan lahan harus dimanfaatkan optimal.

Pemerintah (Kementerian Pertanian RI) telah mencoba untuk memperkenalkan sistem polder ke masyarakat dengan dengan membangun 2 polder di Sumatera Selatan, namun kurang berhasil. Permasalahannya di pemahaman masyarakat untuk berkorban lahan untuk tanggul dan saluran, masyarakat belum mau mengolah lahannya secara intensif seperti swasta, dan masyarakat tidak mau membiayai opera-sional pompa. Penerapan polder mini juga telah diterapkan di Desa Jejangkit Muara, Kabupaten Barito Kuala, Kalimantan Selatan, belum juga berhasil seperti swasta, dengan kendala masyarakat belum mau mengolah lahannya secara intensif, dan biayai operasional pompa.

Sistem polder mini ini berhasil mengendalikan tinggi muka air dilahan sawah, dapat meningkatkan IP dan produk- 
tivitas, namun untuk operasionalnya diperlukan sistem korporasi yang mengendalikan pengelolaan lahan dan operasional pompa.

\section{KESIMPULAN}

Dari uraian diatas dapat disimpulkan sistem polder mini dapat menjadi alternatif pengelolaan air dilahan rawa lebak. Namun untuk dapat berhasilnya diterapkan oleh masyarakat harus didukung oleh sistem korporasi.

\section{UCAPAN TERIMA KASIH}

Ucapan terimakasih disampaikan kepada Pimpinan Fakultas Pertanian Unsri yang telah membiayai penelitian ini pada tahun 2019

\section{DAFTAR PUSTAKA}

Balai Besar Litbang Sumber Daya Lahan Pertanian. 2016. Sumber Daya Lahan Pertanian Indonesia. AARD-Press. Bogor.

Kementan. 2018. Lahan Rawa: Masa Depan Lumbung Pangan Indonesia "Membangkitkan Raksasa Tidur". Kementerian Pertanian. Rep. Indonesia. Jakarta.

Noor, M. dan Mukhlis. 2019. Perspektif Lahan Rawa Sebagai Lumbung Pangan Dunia. Balai Penelitian Pertanian Lahan Rawa. Dalam buku : Sumber Daya Lahan Rawa, Dukungan Teknologi Menuju Lumbung Pangan Dunia 2045. Disunting oleh Masganti, Eni Maftu'ah, M. Noor, Maulia Aries Susanti, R. Smith Simatupang, M. Alwi, Hendri Sosiawan, Mukhlis, Muhammad. 2019. Penerbit PT RajaGrafindo Persada, Depok

Noor, M., I. Khairullah, dan H. Sosiawan, 2019. Pengelolaan Air Untuk Pertanian Tanaman Padi Di Lahan
Rawa: Kasus Desa Jejangkit Muara, Kabupaten Barito Kuala, Kalimantan Selatan. Dalam buku : Sumber Daya Lahan Rawa, Dukungan Teknologi Menuju Lumbung Pangan Dunia 2045. Disunting oleh Masganti, Eni Maftu'ah, M. Noor, Maulia Aries Susanti, R. Smith Simatupang, M. Alwi, Hendri Sosiawan, Mukhlis, Muhammad. 2019. Penerbit PT RajaGrafindo Persada, Depok.

Saleh, E., C. Irsan dan M. U. Harun. 2013. Evaluasi Pola Tanam pada Lahan Rawa Lebak Dangkal Ogan Keramasan. Lembaga Penelitian Universitas Sriwijaya, Indralaya 